\title{
Differential Effect of Adenosine on Anterograde and Retrograde Fast Pathway Conduction in Patients with Atrioventricular Nodal Reentrant Tachycardia
}

\author{
JOSEPH J. SOUZA, M.D., ADAM ZIVIN, M.D., MATTHEW FLEMMING, M.D., \\ FRANK PELOSI, M.D., HAKAN ORAL, M.D., BRADLEY P. KNIGHT, M.D., \\ RAJIVA GOYAL, M.D., K. CHING MAN, D.O., \\ S. ADAM STRICKBERGER, M.D., and FRED MORADY, M.D. \\ From the University of Michigan Medical Center, Ann Arbor, Michigan
}

\begin{abstract}
Adenosine and Retrograde Fast Pathway Conduction. Introduction: Several studies have shown that the fast pathway is more responsive to adenosine than the slow pathway in patients with AV nodal reentrant tachycardia. Little information is available regarding the effect of adenosine on anterograde and retrograde fast pathway conduction.

Methods and Results: The effects of adenosine on anterograde and retrograde fast pathway conduction were evaluated in 116 patients (mean age $47 \pm 16$ years) with typical AV nodal reentrant tachycardia. Each patient received $12 \mathrm{mg}$ of adenosine during ventricular pacing at a cycle length 20 msec longer than the fast pathway VA block cycle length and during sinus rhythm or atrial pacing at $\mathbf{2 0}$ msec longer than the fast pathway AV block cycle length. Anterograde block occurred in $98 \%$ of patients compared with retrograde fast pathway block in $62 \%$ of patients $(\mathrm{P}<0.001)$. Unresponsiveness of the retrograde fast pathway to adenosine was associated with a shorter AV block cycle length ( $374 \pm 78$ vs $333 \pm 74 \mathrm{msec}, \mathrm{P}<0.01$ ), a shorter VA block cycle length $(383 \pm 121$ vs $307 \pm 49$ msec, $P<0.001)$, and a shorter VA interval during tachycardia $(53 \pm 23$ vs $41 \pm 17 \mathrm{msec}, \mathrm{P}<0.01)$.

Conclusion: Although anterograde fast pathway conduction is almost always blocked by 12 mg of adenosine, retrograde fast pathway conduction is not blocked by adenosine in $38 \%$ of patients with typical AV nodal reentrant tachycardia. This indicates that the anterograde and retrograde fast pathways may be anatomically and/or functionally distinct. Unresponsiveness of VA conduction to adenosine is not a reliable indicator of an accessory pathway. ( $\mathrm{C}$ Cardiovasc Electrophysiol, Vol. 9, pp. 820-824, August 1998)
\end{abstract}

adenosine, atrioventricular nodal reentrant tachycardia, fast pathway

Introduction

Recent studies have shown that the fast pathway is more responsive to adenosine than the slow pathway in patients with AV nodal reentrant tachycardia. ${ }^{1,2}$ However, little information is available regarding the relative effects of adenosine on anterograde and retrograde fast pathway conduction. Therefore, the purpose of this study was to com-

Address for correspondence: Fred Morady, M.D., University of Michigan Medical Center, 1500 East Medical Center Drive, Ann Arbor, MI 48109-0022. Fax: 313-936-7026.

Manuscript received 28 April 1998; Accepted for publication 3 June 1998 . pare the responsiveness of anterograde and retrograde fast pathway conduction to adenosine in patients with $\mathrm{AV}$ nodal reentrant tachycardia.

\section{Methods}

\section{Subject Characteristics}

The subjects of this study consisted of 116 patients with typical AV nodal reentrant tachycardia who underwent an electrophysiologic procedure for the purpose of radiofrequency ablation of the slow pathway. Patients with asthma were excluded from the study, as were patients 
in whom adenosine resulted in atrial fbrillation. There were 39 men and 77 women (mean age $47 \pm 16$ years). One hundred seven patients $(92 \%)$ had no evidence of structural heart disease. Six patients had coronary artery disease, one patient had hypertension and left ventricular hypertrophy, and two patients had nonischemic cardiomyopathy. Echocardiography demonstrated a normal left ventricular ejection fraction in 112 patients $(96 \%)$.

\section{Electrophysiologic Testing}

The electrophysiologic procedures were performed after obtaining informed, written consent and after the discontinuation of antiarrhythmic drug therapy for at least five half-lives. Three quadripolar electrode catheters were inserted into a femoral vein and positioned in the high right atrium, His-bundle position, and right ventricular apex. Atrial and ventricular pacing were performed at twice diastolic threshold using a programmable stimulator (Bloom DTU 210, Bloom Associates, Narbeth, PA, USA). Leads I, II, III, and $\mathrm{V}_{1}$, and the intracardiac electrograms were simultaneously recorded on paper using a Mingograph 7 recorder (Siemens-Elema, Solna, Sweden) and on optical disk (Quinton Electrophysiology Corp., Seattle, WA, USA). Electrograms were filtered at 50 to $500 \mathrm{~Hz}$.

The diagnosis of typical AV nodal reentrant tachycardia was made using established criteria. ${ }^{3}$ If $\mathrm{AV}$ nodal reentrant tachycardia was not inducible in the baseline state, isoproterenol ( 1 to $4 \mu \mathrm{g} / \mathrm{min}$ ) was infused to facilitate tachycardia induction. The electrophysiologic parameters that were measured included AV and VA block cycle lengths, AV nodal reentrant tachycardia cycle length, and the VA interval during tachycardia measured in the high right atrium. If isoproterenol was required to induce $\mathrm{AV}$ nodal reentrant tachycardia, the electrophysiologic variables were measured during isoproterenol infusion. The high right atrial electrogram was used for measuring the VA interval because its onset was more easily identifable than the onset of the septal atrial electrogram.

To assess decremental conduction in the retrograde fast pathway, the VA interval during ventricular pacing in the setting of sinus rhythm was measured in the last 57 patients in the study. The VA intervals were compared at two ventricular pacing cycle lengths: 20 msec shorter than the sinus cycle length, and $20 \mathrm{msec}$ longer than the VA block cycle length (Fig. 1).

\section{Study Protocol}

After the presence of typical AV nodal reentrant tachycardia was established and the electrophysiologic parameters were measured, each patient received a 12-mg injection of adenosine into a femoral vein during ventricular pacing at a cycle length $20 \mathrm{msec}$ longer than the fast pathway VA block cycle length. The adenosine injection was followed immediately by injection of a 10-cc saline bolus. If VA block occurred, ventricular pacing was stopped and atrial pacing was immediately started at a cycle length $20 \mathrm{msec}$ longer than the anterograde (AV) fast pathway block cycle length, to assess whether there was AV block in response to the same injection of adenosine (Fig. 2). If VA block did not occur, radiofrequency ablation of the slow pathway was performed. After ablation of the slow pathway, another 12-mg bolus of adenosine was injected during atrial pacing at a cycle length $20 \mathrm{msec}$ longer than the fast
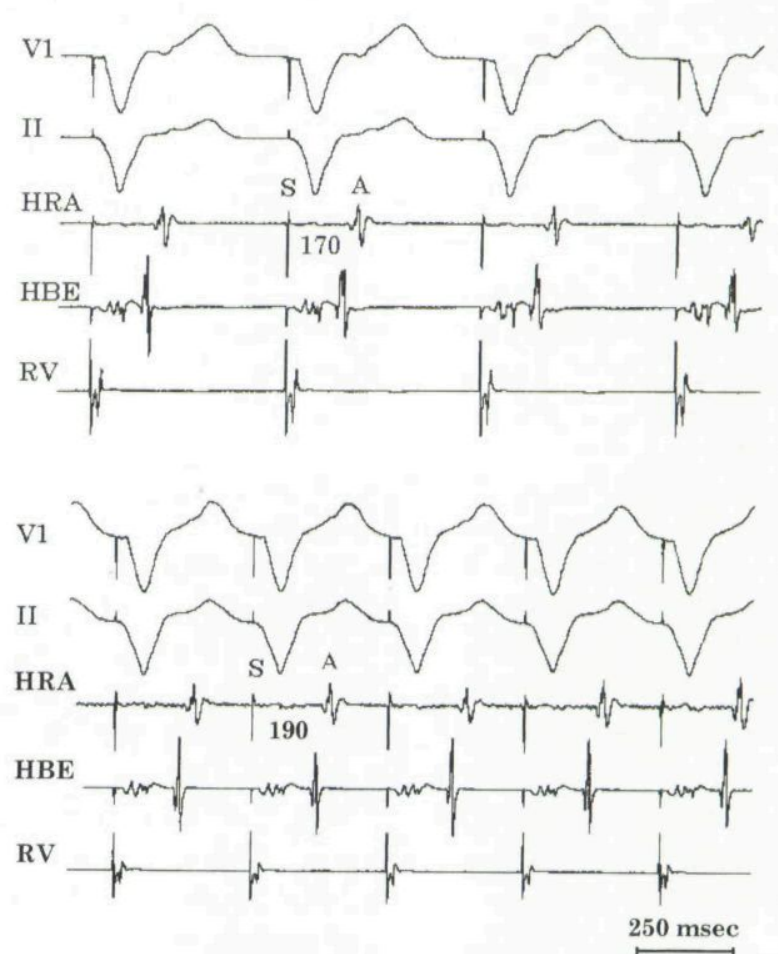

Figure 1. Example of how decremental conduction in the retrograde fast pathway was assessed. (Top panel) The VA conduction during ventricular pacing at $20 \mathrm{msec}$ shorter than the sinus cycle length is $170 \mathrm{msec}$. (Bottom panel) The VA conduction during ventricular pacing at 20 msec longer than the VA block cycle length is $190 \mathrm{msec}$. Surface leads VI and II are shown along with three intracardiac electrograms. HRA = high right atrial electrogram; HBE $=$ His-bundle electrogram; $R V A=$ right ventricular apex electrogram. 


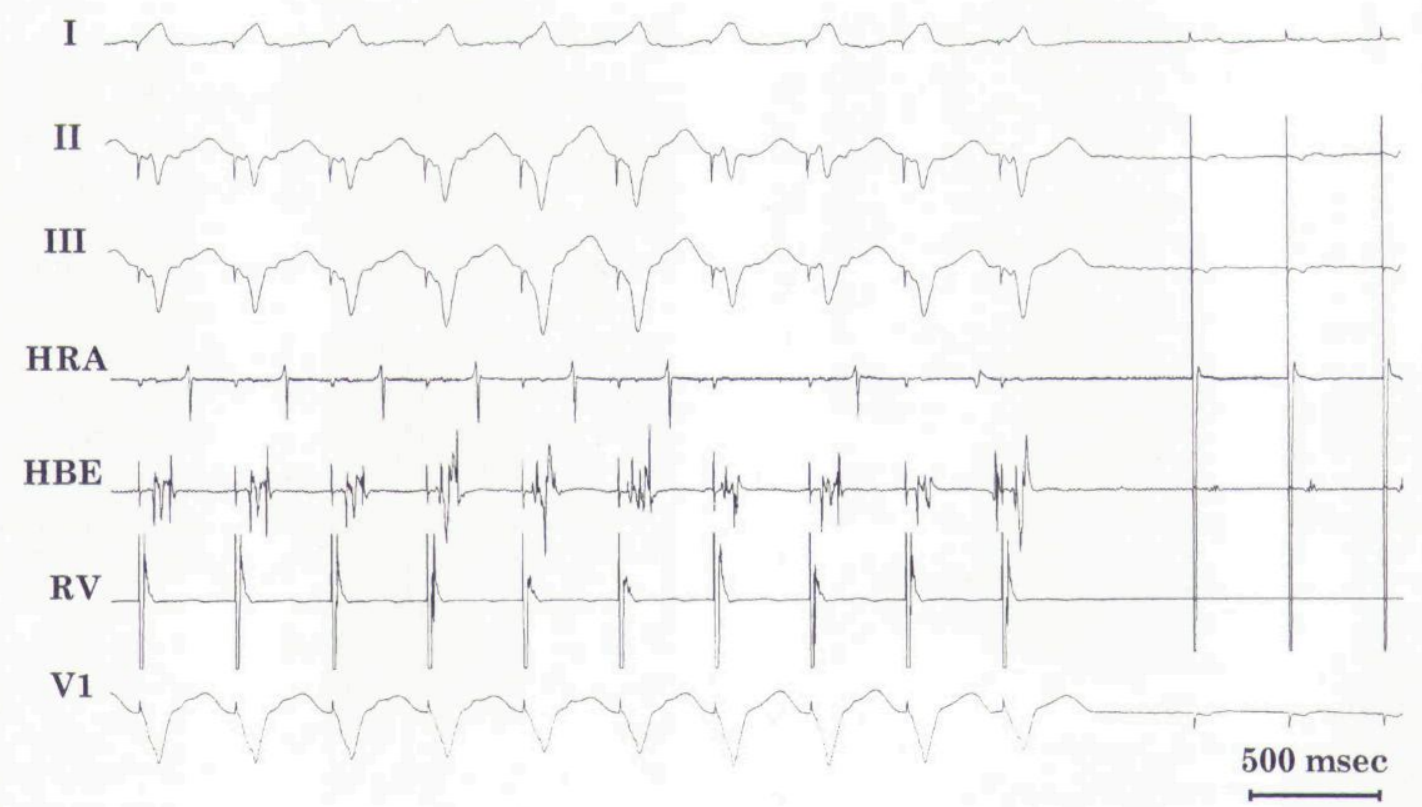

Figure 2. Example of VA and AV block in response to adenosine. Abbreviations as in Figure 1.

pathway anterograde AV block cycle length, to look for AV block.

\section{Statistical Analysis}

Continuous variables are expressed as mean \pm $1 \mathrm{SD}$ and were compared using Student's $t$-test. Chi-square analysis was used to compare the frequencies of anterograde and retrograde fast pathway block in response to adenosine. $\mathrm{P}<0.05$ was considered significant.

\section{Results}

In response to adenosine, anterograde fast pathway block occurred in 114 (98\%) of 116 patients, whereas retrograde fast pathway block occurred in $72(62 \%)$ of 116 patients $(\mathrm{P}<0.001)$. The baseline AV block cycle length, VA block cycle length, and VA interval during tachycardia were significantly shorter in patients who did not demonstrate retrograde fast pathway block in response to adenosine than in those who did (Table 1). The mean cycle length of AV nodal reentrant tachycardia did not differ significantly between patients who did and did not have retrograde fast pathway block in response to adenosine (Table 1). The degree of retrograde decremental conduction in the fast pathway also did not differ between patients who did and did not have retrograde fast pathway block in response to adenosine (Table 1).

Fifty-eight patients required isoproterenol to initiate typical $\mathrm{AV}$ nodal reentrant tachycardia. Ret- rograde fast pathway block occurred in $38(66 \%)$ of 58 patients requiring isoproterenol and in 34 $(59 \%)$ of 58 patients not requiring isoproterenol to induce $\mathrm{AV}$ nodal reentrant tachycardia $(\mathrm{P}=0.44)$.

\section{Discussion}

\section{Main Findings}

The main finding of this study is that $38 \%$ of patients with typical $\mathrm{AV}$ nodal reentrant tachycardia did not demonstrate retrograde fast pathway block in response to adenosine. In contrast, anterograde fast pathway block occurred in almost $100 \%$ of patients. Shorter AV and VA block cycle lengths and a shorter VA interval measured during AV nodal reentrant tachycardia were associated with the absence of VA block in response to adenosine. Isoproterenol was needed to initiate tachycardia in $50 \%$ of patients, but its use did not influence the effect of adenosine on the retrograde fast pathway. The differential response of anterograde and retrograde conduction to adenosine suggests that the anterograde and retrograde fast AV nodal pathways may be anatomically and/or functionally distinct.

\section{Anterograde and Retrograde Fast Pathways: Anatomic Considerations}

The concept of anatomically distinct anterograde and retrograde fast pathways is supported by a study 
TABLE 1

Measured Electrophysiologic Parameters in Patients who Demonstrate and do not Demonstrate Retrograde Fast Pathway Block in Response to Adenosine

\begin{tabular}{lccc}
\hline & $\begin{array}{c}\text { No } \\
\text { Retrograde } \\
\text { Block }\end{array}$ & $\begin{array}{c}\text { Retrograde } \\
\text { Block }\end{array}$ & P Value \\
\hline AVBCL (msec) & $374 \pm 78$ & $333 \pm 74$ & $<0.01$ \\
VABCL (msec) & $383 \pm 121$ & $307 \pm 49$ & $<0.001$ \\
VA Interval (msec) & $53 \pm 23$ & $41 \pm 17$ & $<0.01$ \\
TCL (msec) & $344 \pm 78$ & $324 \pm 50$ & 0.14 \\
$\Delta$ VA (msec) & $11 \pm 34$ & $7 \pm 35$ & 0.75 \\
\hline
\end{tabular}

$\mathrm{AVBCL}=\mathrm{AV}$ block cycle length; $\mathrm{VABCL}=\mathrm{VA}$ block cycle length; $\mathrm{VA}$ interval = $\mathrm{VA}$ interval during tachycardia; $\mathrm{TCL}=$ tachycardia cycle length; $\Delta \mathrm{VA}=$ amount of decremental VA conduction between fast and slow ventricular pacing.

in which six patients with AV nodal reentrant tachycardia underwent intraoperative ice mapping. ${ }^{4}$ Minimal PR interval prolongation was noted after tachycardia termination with cooling in the area of the retrograde fast pathway. A large increase in the PR interval should have occurred if the anterograde and retrograde fast pathways were identical. In accord with the results of the present study, these data demonstrated that the anterograde and retrograde fast pathways are anatomically distinct.

Recent data argue against a single, anatomically discrete retrograde pathway. Retrograde atrial activation patterns during tachycardia and right ventricular pacing were studied in 46 patients with typical AV nodal reentrant tachycardia. ${ }^{5}$ Multiple sites of earliest activation were noted during AV nodal reentrant tachycardia and ventricular pacing, and there was only $39 \%$ concordance between the retrograde atrial activation sequences during AV nodal reentrant tachycardia and right ventricular pacing. Whether the variable response to adenosine found in the present study can be explained by anatomic differences in the fast pathway is unknown.

\section{Previous Studies with Adenosine or Adenosine Triphosphate}

In the early 1980s, Belhassen and colleagues ${ }^{6}$ reported VA block in $5(56 \%)$ of 9 patients who received $20 \mathrm{mg}$ of adenosine-5'-triphosphate (ATP) during right ventricular pacing. They hypothesized that ATP could influence conduction in the retrograde final common pathway on some patients. They also suggested that some patients may have ATP-resistant retrograde conduction or perhaps extranodal retrograde pathways. Their data are in agreement with the present study.
Consistent with the results of the present study, functional differences between AV nodal slow and fast pathways also have been described. Adenosine produced AV block more easily in the anterograde fast pathway compared with the slow pathway. ${ }^{1}$ Curtis et al. ${ }^{2}$ examined the effect of incremental doses of adenosine on anterograde fast and slow pathway conduction in patients with typical AV nodal reentrant tachycardia. Their study showed that block in the anterograde fast pathway consistently occurred at lower doses of adenosine compared with the anterograde slow pathway (2.7 $\pm 3.0 \mathrm{mg}$ vs $7.2 \pm 4.7 \mathrm{mg}$ ). Furthermore, the effective refractory period of each pathway was inversely correlated with the dose of adenosine required to block the pathway. Our data are similar in that the mean AV and VA block cycle lengths were longer in patients who demonstrated retrograde fast pathway block in response to adenosine.

A small study evaluated the effect of adenosine on anterograde and retrograde fast pathway conduction in 17 patients with typical AV nodal reentrant tachycardia. ${ }^{7}$ Incremental doses of adenosine, starting at $0.5 \mathrm{mg}$, were given until block occurred. Anterograde fast pathway block occurred with lower doses of adenosine compared with retrograde fast pathway block $(3.4 \pm 1.4 \mathrm{mg}$ vs $8.2 \pm 2.9$ $\mathrm{mg}$ ). Additionally, retrograde fast pathway block was enhanced by intravenous verapamil, suggesting that the retrograde fast pathway involves AV nodal tissue. Our study did not use incremental doses of adenosine, but instead used a single 12-mg intravenous injection followed by a 10-cc saline bolus. This was chosen because we wanted to determine the frequency of anterograde and retrograde fast pathway block using a clinically relevant dose of adenosine. ${ }^{8}$ The frequency of VA block in response to a specific dose of adenosine was not possible with the design of the prior study. ${ }^{?}$

\section{Adenosine and Accessory Pathway Ablation}

A study by Keim and colleagues ${ }^{9}$ was the first to suggest that adenosine-induced $\mathrm{AV}$ and VA block after radiofrequency ablation of an accessory pathway is a reliable indicator of a successful ablation procedure. A much larger study in 116 patients confirmed their findings. ${ }^{10}$ However, the present study demonstrates that $38 \%$ of patients will not develop retrograde fast $\mathrm{AV}$ nodal pathway block in response adenosine. Therefore, the lack of VA block after adenosine injection is not specific for persistent accessory pathway function after radiofrequency ablation. 


\section{Limitations}

Unlike previous studies, we did not use incremental doses of adenosine. Instead, a single clinically relevant dose of $12 \mathrm{mg}$ was used to evaluate anterograde and retrograde fast pathway block. Therefore, the results of this study are not applicable to doses of adenosine higher or lower than $12 \mathrm{mg}$.

A possible limitation of this study is that the effect of adenosine on anterograde fast pathway conduction in some patients was assessed only after slow pathway ablation. Because slow pathway ablation may modify the properties of the fast pathway, ${ }^{11}$ it is possible that the responsiveness of the fast pathway to adenosine was modified by slow pathway ablation. However, because slow pathway ablation results in shortening of fast pathway refractoriness, ${ }^{11}$ it is unlikely that slow pathway ablation resulted in heightened sensitivity of the fast pathway to adenosine. Therefore, the finding that adenosine caused anterograde fast pathway block in $98 \%$ of patients is unlikely to have been influenced by slow pathway ablation.

\section{Clinical Implications}

Adenosine almost always produces anterograde fast pathway block, whereas it produces retrograde fast pathway block in approximately $60 \%$ of patients. This differential effect of adenosine may reflect a combination of anatomic and/or functional differences between anterograde and retrograde fast pathways. In patients who have undergone radiofrequency ablation of an accessory pathway and still have 1:1 VA conduction, the absence of VA block in response to adenosine does not necessarily imply that accessory pathway conduction is still present.

\section{References}

1. Tebbenjohanns J, Pfeiffer D, Schumacher B, et al: Differential sensitivity of fast and slow pathways to adenosine: Further insights into dual AV nodal physiology from catheter ablation. (Abstract) PACE 1996; 19:648.

2. Curtis AB, Belardinelli L, Woodard DA, et al: Induction of atrioventricular nodal reentrant tachycardia with adenosine: Differential effects of adenosine on fast and slow atrioventricular node pathways. J Am Coll Cardiol 1997;30:1778-1784.

3. Josephson ME. Clinical Cardiac Electrophysiology: Techniques and Interpretations. Lea \& Febiger, Philadelphia, 1993, pp. 181-224.

4. Keim S, Werner P, Jazayeri M, et al: Localization of the fast and slow pathways in atrioventricular nodal tachycardia by intraoperative ice mapping. Circulation 1992;86:919-925.

5. Anselme F, Hook B, Monahan K, et al: Heterogeneity of retrograde fast-pathway conduction pattern in patients with atrioventricular nodal reentry tachycardia: Observations by use of simultaneous multisite catheter mapping of Koch's triangle. Circulation 1996;93:960-968.

6. Belhassen B, Pelleg A, Shoshani D, et al: Electrophysiologic effects of adenosine- 5 '-triphosphate on atrioventricular reentrant tachycardia. Circulation 1983;68:827-833.

7. Lee CS, Lai WT, Wu JC, et al: Differential effects of adenosine on antegrade and retrograde fast pathway conduction in atrioventricular node reentry. Am Heart J 1997;134:799-806.

8. DiMarco JP, Miles W, Akhtar M, et al: Adenosine for paroxysmal supraventricular tachycardia: Dose ranging and comparison with verapamil. Ann Intern Med 1990;113:104-110.

9. Keim S, Curtis AB, Belardinelli L, et al: Adenosine-induced atrioventricular block: A rapid and reliable method to assess surgical and radiofrequency catheter ablation of accessory atrioventricular pathways. J Am Coll Cardl 1992;19:1005-1012.

10. Walker KW, Silka MJ, Haupt D, et al: Use of adenosine to identify patients at risk for recurrence of accessory pathway conduction after initially successful radiofrequency catheter ablation. PACE 1995;18:441-446.

11. Strickberger SA, Daoud E, Niebauer M, et al: Effects of partial and complete ablation of the slow pathway on fast pathway properties in patients with atrioventricular nodal reentrant tachycardia. J Cardiovasc Electrophysiol 1994;5:645-649. 
This document is a scanned copy of a printed document. No warranty is given about the accuracy of the copy. Users should refer to the original published version of the material. 